\title{
Neutrophil and macrophage responses to inflammation in the peritoneal cavity of rainbow trout Oncorhynchus mykiss. A light and electron microscopic cytochemical study
}

\author{
António Afonso ${ }^{1,2, *}$, Susana Lousada ${ }^{1}$, Joana Silva ${ }^{1}$, Anthony E. Ellis ${ }^{3}$, Manuel T. Silva ${ }^{1}$ \\ 'Institute of Molecular and Cellular Biology, University of Porto, Rua do Campo Alegre, 823, P-4150 Porto, Portugal \\ ${ }^{2}$ CIMAR, Abel Salazar Biomedical Institute, University of Porto, Largo Professor Abel Salazar, P-4000 Porto, Portugal \\ ${ }^{3}$ Marine Laboratory, Victoria Road, Aberdeen AB11 9DB, United Kingdom
}

\begin{abstract}
The neutrophil and macrophage responses that accompany inflammation were studied in the peritoneal cavity of rainbow trout Oncorhynchus mykiss using light and electron microscopic cytochemistry. Neutrophils of inflammatory peritoneal exudates were alpha-naphthyl butyrate esterasenegative, peroxidase-positive and rich in cytoplasmic glycogen granules. Macrophages were poor in glycogen, esterase-positive and usually peroxidase-negative. Some peroxidase-positive macrophages were due to the transfer to macrophages of neutrophilic peroxidase. The ultrastructural double labelling for glycogen/peroxidase or esterase/peroxidase was most useful for precisely characterising neutrophils and macrophages in the inflamed peritoneal cavities and for correctly labelling peroxidasepositive macrophages. Intraperitoneal injection of casein, Incomplete Freund's Adjuvant (IFA) and live or formol-killed Yersinia ruckeri resulted in a rapid influx of neutrophils, peaking at 24 to $48 \mathrm{~h}$ postinjection and reaching values, in the case of live bacteria, $500 \times$ those in the resting, unstimulated peritoneal cavity. Peritoneal macrophages also increased, but the response was slower (peak at 5 d) and with more modest increases in number $(7.5 \times)$. Neutrophil and mononuclear cells returned to normal values after $15 \mathrm{~d}$ in the case of casein and bacteria, but continued above base values $30 \mathrm{~d}$ after the injection of IFA. Conversely, after the injection of phosphate buffered saline, India ink or with shaminjections, very moderate neutrophil and macrophage responses subsided in a few hours. Phagocytosis of bacteria was studied by light microscopy of preparations stained for peroxidase by a new method which allows for the simultaneous observation of intracellular bacteria and peroxidase staining. When $Y$. ruckeri was injected into resting peritoneal cavities, bacteria were ingested by the resident macrophages. When the bacteria were injected into cavities with high numbers of neutrophils (due to the previous injection of casein), more neutrophils than macrophages contained bacteria. Results show that the macrophages are the resident phagocytes of the peritoneal cavity of trout, while neutrophils are present in that body cavity in significant numbers only in situations of inflammation and only as long as the inflammation persists.
\end{abstract}

KEY WORDS: Rainbow trout leukocytes - Rainbow trout peritoneal leukocytes - Rainbow trout neutrophils - Neutrophils in inflammation - Cytochemistry of trout phagocytes

\section{INTRODUCTION}

Phagocytosis, killing and degradation of invading microrganisms by specialised phagocytes, is a crucial

·E-mail: aafonso@gaia.ibmc.up.pt process in the defense of vertebrates against some infections (Mackaness 1969, Ellis 1977, Adams \& Hamilton 1984, Edwards \& Kirkpatrick 1986, Lehrer et al. 1988, Hine 1992, Brown 1995). It is interesting that mammals, teleosts and other higher eukaryotes utilize 2 types of phagocytic cells-neutrophils and macrophages - in the defense against infection (Rowley et 
al. 1988, Secombes \& Fletcher 1992, Brown 1995). From studies conducted with mammals, data on the behaviour of each of the 2 phagocytes during inflammation, including that caused by infection, can be summarised as follows (Lehrer et al. 1988, Haslett et al. 1989, Silva et al. 1989, van Furth 1992, Densen et al. 1995, Kubicka et al. 1996). Neutrophils are present in large numbers in blood and hematopoietic organ pools as a reserve, and, under normal conditions, are rare in the tissues and body cavities. In contrast, macrophages are present in all body compartments, and, therefore, are the first phagocytes to encounter the invading microrganisms when superficial barriers are breached. Neutrophils from the reserve pools are quickly attracted to the infectious foci by microbial products and by chemotactic agents produced by immune cells including macrophages (Lehrer et al. 1988, Appelberg 1992). Monocytes, the blood circulating precursors of tissue macrophages, are also recruited to infectious sites, where they cause an increase in the initial macrophage population.

Researchers at this laboratory have been interested in investigating whether a pattern of distribution and mobilization of the 2 phagocytes similar to that described above for mammals occurs in fish. In the present paper we expand upon previous observations of the leucocyte population of the resting peritoneal cavity of rainbow trout Oncorhynchus mykiss (Afonso et al. 1997) by analyzing the response of neutrophils and macrophages during inflammation. The peritoneal model (Silva et al. 1989, Appelberg et al. 1991, Pestana 1994, Sousa 1994) was used because, in contrast to what occurs in solid organs, the peritoneal cell response that accompanies intraperitoneal inflammation can be easily studied both qualitatively and quantitatively. This is so because the leucocytes in peritoneal exudates largely remain a dispersed population, which is, therefore, amenable to precise methods of cytological analysis (Silva et al. 1989. Afonso et al. 1997). Moreover, the phagocyte response to inflammation in the peritoneal cavity is representative of that seen in tissues (van Furth 1992).

Sometimes, with conventional cytological procedures, it is difficult to distinguish neutrophils and macrophages in the inflammatory peritoneal exudates. Therefore, light and electron microscopic cytochemical methods were used to analyze the peritoneal phagocyte response to the presence of infectious agents.

The present study extends our knowledge gained from previous observations (Afonso et al. 1997) and shows that, in rainbow trout, neutrophils and macrophages display different patterns of localization in the normal host and of mobilization into inflamed areas. These patterns are similar to those seen in mammals.

\section{MATERIALS AND METHODS}

Experimental fish. Sexually immature rainbow trout weighing between 100 and $200 \mathrm{~g}$, purchased from a commercial farm, were maintained in recirculating aerated fresh water, at $15^{\circ} \mathrm{C}$, and were fed ad libitum on commercial pellets. The fish to be injected with phlogistic agents were transferred to $600 \mathrm{l}$ fibreglass tanks under the same conditions as above, where they were maintained for at least $15 \mathrm{~d}$ before the study. Only healthy fish, as indicated by their activity and exterior appearance, were used.

Growth, harvesting and treatment of bacterial agents. The strain FP-3 of Yersinia ruckeri type 1 was kindly supplied by Prof. J. Barja (University of Santiago de Compostela, Spain). Details of the preparation of bacterial suspensions are given elsewhere (Afonso et al. 1998). Preliminary infectivity tests showed that, for the conditions used in this work, this bacterium does not induce a progressive infection. Formol-killed bacteria were prepared by treating suspensions in phosphate buffered saline (PBS) adjusted to $310 \mathrm{mOsm}$ $\mathrm{I}^{-1}$ with $8 \%$ formaldehyde for $3 \mathrm{~d}$, followed by 5 washings with PBS. Plating of the formol-treated bacteria showed $100 \%$ killing. For fish inoculation, concentrated, frozen suspensions of live or killed bacteria were thawed at room temperature and diluted to the desired concentrations (see below) with PBS.

Intraperitoneal injection of phlogistic agents. The following agents were injected intraperitoneally (i.p.) in volumes of $100 \mu \mathrm{l}: 0.4 \%$ India ink in PBS; $12 \%$ casein in water; undiluted Incomplete Freund's Adjuvant (IFA); suspensions of live or formol-killed Yersinia ruckeri $\left(5 \times 10^{7}\right.$ bacteria per fish).

Live Yersinia ruckeri was also injected i.p. in trout with peritoneal cavities previously inflamed by the i.p. injection of $100 \mu \mathrm{l}$ of $12 \%$ casein in water $48 \mathrm{~h}$ before the bacterial challenge. The inoculum $\left(3 \times 10^{8}\right.$ per fish $)$ was higher than that administered to fish with resting peritoneal cavities because the number of phagocytes (macrophages plus neutrophils) was higher in the peritoneal cavities of fish previously injected with casein $\left(144.48 \times 10^{6}\right)$ as compared to untreated fish $\left(1.74 \times 10^{6}\right)$.

Intraperitoneal injections were carried out as described (Afonso et al. 1997). Control fish were injected i.p. with PBS or subjected to a sham injection by inserting the needle into the peritoneal cavity without injection

Collection of peritoneal leucocytes. The peritoneal cells were collected at intervals (see Tables $1 \& 2$, and Fig. 7) after the i.p. injections using a procedure previously described in detail (Afonso et al. 1997). The peritoneal cell suspension was analysed within minutes after collection for several morphological and cytochemical parameters as follows 
Light microscopy of peritoneal leucocytes. Total cell counts were performed with a haemocytometer. Cytospin preparations were made with a Shandon Cytospin 2. The cytospins were stained with Wright's stain (Haemacolor, Merck) after fixation for $1 \mathrm{~min}$ with formol-ethanol $(10 \mathrm{ml}$ of $37 \%$ formaldehyde and $90 \mathrm{ml}$ of absolute ethanol) (Kaplow 1965). The leucocytes in the peritoneal exudates were differentially counted as neutrophils and mononuclear cells, except in some situations when mononuclear leucocytes were further distinguished as macrophages and lymphocytes (see 'Results'). As described previously for the resting peritoneal leucocyte population of rainbow trout (Afonso et al. 1997), some peritoneal mononuclear leucocytes could not be classified with certainty. These cells, referred to as 'non-classified leucocytes' (Afonso et al. 1997), were present in the inflammatory peritoneal exudates studied here in percentages well below (less than $5 \%$ of total leucocytes) those reported for the resting peritoneal cavities. These cells were included in the class 'mononuclear leucocytes'.

Electron microscopy of peritoneal leucocytes. The peritoneal leucocyte suspension in PBS was processed for electron microscopy as described (Silva et al. 1971, Silva \& Macedo 1983, Silva et al. 1987, Afonso et al. 1997).

To enhance the electron density of glycogen, some samples were processed using $2 \% \mathrm{OsO}_{4}$ in $0.1 \mathrm{M}$ cacodylate buffer $\mathrm{pH} 7.3$, supplemented with $3 \%$ potassium ferrocyanide (Karnowsky 1971, Robinson et al. 1982) as fixative.

Observations and micrographs were done with a Zeiss EM $10 \mathrm{C}$ electron microscope

Cytochemistry. For peroxidase detection by light microscopy 2 methods were used. One is the classic technique of Kaplow (1965). This method is quite efficient but has 2 major disadvantages, namely: (1) the peroxidase staining is quite light-sensitive and fades in a few days, and (2) it stains the peroxidase-positive sites a very deep blue, making it difficult to visualize bacteria inside neutrophils.

Because of these drawbacks, a new method was devised which is referred to in the present paper as the Antonow method. It is carried out as follows:

(1) Fixation of the cytospin preparations is done with formol-ethanol as in Kaplow's method (1965).

(2) After rinsing with running tap water for a few seconds, the preparations were treated with a 1/30 dilution (in water) of Kaplow's reagent (without safranin) for 5 to $10 \mathrm{~min}$ at room temperature. The diluted reagent was prepared fresh or kept frozen.

(3) To counterstain the preparations the Wright or the Gram stain was used.

For ultrastructural detection of peroxidase activity the method of Robbins et al. (1971) was followed. Con- trols were carried out for all techniques by omitting hydrogen peroxide from the incubation mixtures.

To test the resistance of trout neutrophilic peroxidase to cyanide the method described by Horton et al. (1996) was used; the incubation reagent contained $8 \mathrm{mM} \mathrm{NaCN}$.

Ultrastructural detection of alpha-naphthyl butyrate (ANB) esterase was carried out as described by Bozdech \& Bainton (1981), with postfixation with $1 \%$ osmium tetroxide in distilled water with $\mathrm{pH}$ adjusted to 7.6 to heighten the contrast of the reaction product (Bozdech \& Bainton 1981). In some samples, the ANB esterase staining was followed by the peroxidase technique carried out as indicated above (Robbins et al. 1971).

The ultrastructural staining of cytoplasmic polysaccharides, most likely glycogen, was carried out using the original method of Thiéry (1967), or a modification (Silva \& Macedo 1987). Thiéry staining was applied to ultrathin sections of samples processed as described above for conventional electron microscopy or for peroxidase ultrastructural cytochemistry.

Study of blood monocytes. Monocytes in the blood of normal rainbow trout were studied in concentrated blood leucocytes obtained by the method described by Thuvander et al. (1987) and applied to heparinised venous blood collected from the caudal vein. These leucocyte preparations were analysed for peroxidase, esterase and glycogen using the methods described above for peritoneal leucocytes.

\section{RESULTS}

\section{Cytochemistry for peroxidase of inflammatory peritoneal neutrophils and macrophages}

Kaplow's technique strongly stains peroxidase in cytoplasmic granules of inflammatory neutrophils (Fig. 1a, b). The dark-blue staining is very intense and is most useful for detecting very reduced amounts of the enzyme activity, as was the case for some macrophages in the inflamed cavities which showed only a few small peroxidase-positive cytoplasmic granules (Fig. 1b).

Utilization of Antonow's technique to detect peroxidase activity results in a green staining of the neutrophil cytoplasmic granules (Fig. 1c-f). Individual granules are sometimes visible (Fig. 1c), but, more frequently, a more or less homogeneously stained cytoplasm is present (Fig. 1d-f). The specificity of the technique is the same as with the conventional Kaplow method, the staining being abolished by omitting hydrogen peroxide from the incubation mixture.

The green peroxidase staining is light insensitive and remains stable for more than 1 yr (the time tested so far). In contrast to what happens with the conventional 

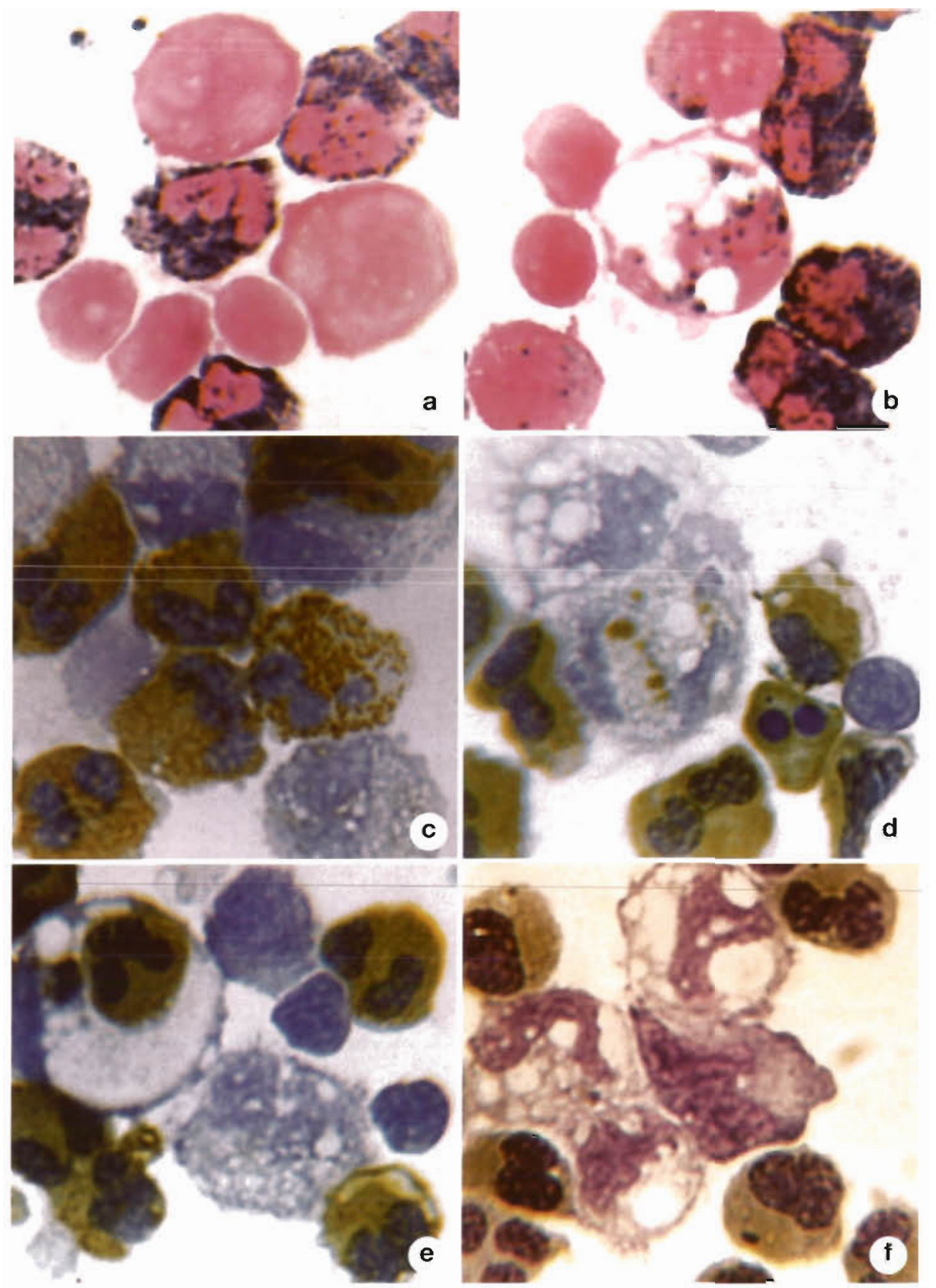

Fig. 1. (a) Oncorhynchus mykiss. Peritoneal leucocytes from a rainbow trout injected i.p. with live Yersinia ruckeri. Sample collected $24 \mathrm{~h}$ post-injection and stained for peroxidase using Kaplow's method. The neutrophils have abundant peroxidase-positive (blue) granules. Mononuclear cells, including 2 macrophages, are peroxidase-negative. $\times 850$. (b) Same sample as in (a), also stained for peroxidase using Kaplow's method. The neutrophils have abundant peroxidase-positive granules. The 3 macrophages have a few peroxidase-positive granules. Two lymphocytes are peroxidase-negative. $\times 850$. (c) Peritoneal cells from a fish injected i.p. with live Y. ruckeri. Sample collected $2 \mathrm{~d}$ after injection and stained for peroxidase using Antonow's method (Wright counterstaining). One neutrophil shows numerous, well-defined, peroxidase-positive (green) cytoplasmic granules. The other neutrophils have a more compact cytoplasmic peroxidase staining. The macrophages present in the field are peroxidase-negative $\times 850$. (d) Peritoneal cells from a fish injected i.p. with live Y. ruckeri. Sample collected 2 d after injection and stained for peroxidase using Antonow's method (Wright counterstaining). Several neutrophils (one with nuclear alterations suggestive of apoptosis) show an intense peroxidase-positive (green) staining. One macrophage is peroxidase-negative, whereas the other has a few peroxidase-positive inclusions. $\times 850$. (e) Same sample as in (d), also stained for peroxidase usıng Antonow's method (Wright counterstaining). Notice the macrophage which had phagocytosed a neutrophil. The other macrophage is peroxidase-negative. $\times 850$. (f) Peritoneal cells from a fish injected i.p. with live $Y$ ruckeri. Sample collected $24 \mathrm{~h}$ after injection and stained for peroxidase using Antonow's method (Wright countersaining). Notice a bacterium inside a neutrophil. The macrophages present in this field are peroxidase-negative. $\times 850$ 
Kaplow method, staining using Antonow's technique allows for a clear visualization of intraneutrophilic bacteria, whether the counterstain is carried out with the Wright or with the Gram stain. In the former case bacteria appear blue against a green background (Fig. 1f). In the case of Gram-positive bacteria, where the Gram stain is used, bacteria appear blue-black against a green background (not shown). Because the counterstaining can be done with the Wright stain, identification of leucocytes is easier with the Antonow's than with Kaplow's method, which uses safranin as a counterstain (cf. Fig. 1a, b).

Some inflammatory mononuclear leucocytes with morphological characteristics typical of macrophages contain peroxidase activity (Fig. 1b, d, e, and see Figs. $4 \& 6$ ). The patterns of peroxidase staining were typically different for neutrophils and peroxidasepositive macrophages. In neutrophils, the staining was quite homogeneous, activity being present in abundant granules which filled most of the cytoplasm of the phagocyte (Fig. 1a-f). In peroxidase-positive macrophages, the staining was rather heterogeneous, showing a range of characteristics from the presence of discrete small peroxidase-positive granules (Fig. 1b) to the presence of small (Fig. 1d) or large vacuoles filled with peroxidase-positive material or even intact neutrophils with peroxidase-positive granules (Fig 1e).

The peroxidase staining of trout neutrophilic granules was resistant to $8 \mathrm{mM} \mathrm{NaCN}$ when assayed by the diaminobenzidine technique described by Horton et a.l. (1996)

Inflammatory neutrophils were seen by electron microscopy to contain numerous peroxidase-positive granules of varying sizes and shapes (Figs. $2 \& 3$ ). When bacteria were present inside neutrophilic phagocytic vacuoles, peroxidase activity was also present in the vacuoles (Fig. 2), indicating that fusion of cytoplasmic granules with the phagosome had occurred.

\section{Polysaccharide granules of neutrophils and macrophages}

Abundant glycogen granules were consistently seen in the cytoplasm of neutrophils when adequate techniques were used (Fig. 3). In macrophages these inclusions were always scarce (Fig. 4), except when, occa-

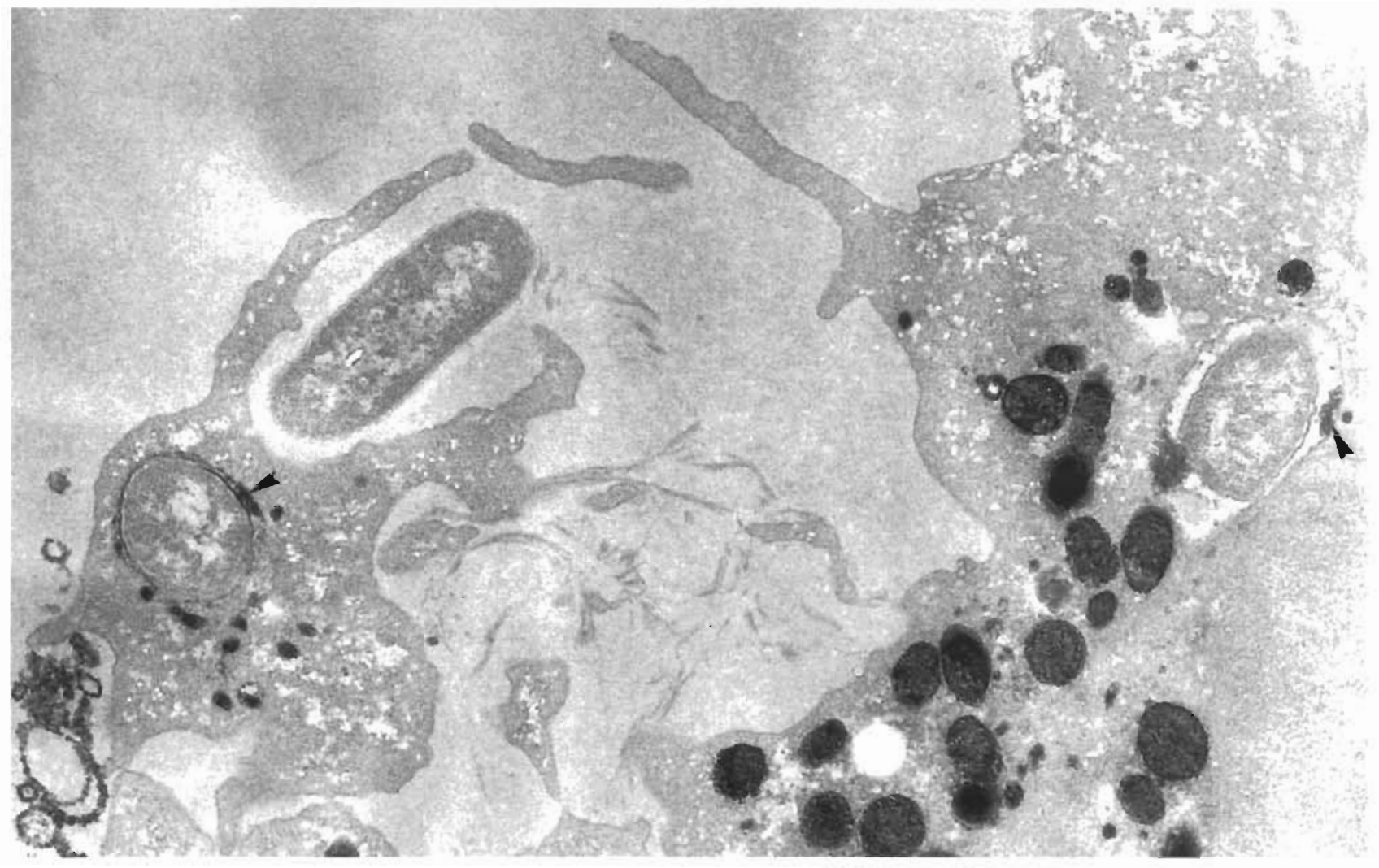

Fig. 2. Two neutrophil fragments in a peritoneal exudate of a trout inoculated i.p. with live Yersinia ruckeri $16 \mathrm{~h}$ before the harvesting of the peritoneal leucocytes. Sample processed for peroxidase and post-fixed with osmium tetroxide in acetate-veronal buffer. Notice the peroxidase-positive neutrophil granules and peroxidatic reaction in 2 phagocytic vacuoles containing bacteria (arrowheads). The neutrophilic cytoplasm has numerous small electron-transparent areas, which are unstained glycogen granules. One bacterium was in the process of being phagocytosed. Section contrasted with lead citrate. $\times 13640$ 
sionally, clusters of polysaccharide granules were found in phagocytic vacuoles or in intramacrophagic neutrophils.

\section{Ultrastructural detection of ANB-esterase}

Electron microscopy of rainbow trout peritoneal phagocytes stained for the detection of ANB esterase showed, as reported for mammals (Bozdech \& Bainton 1981), a characteristic dense staining of the surface of macrophages whereas neutrophils were negative. The simultaneous staining for esterase and peroxidase showed resident macrophages of the resting peritoneal cavity and some macrophages in the inflamed cavities with an esterase-positive surface and no peroxidase-positive sites (Fig. 5), and neutrophils with peroxidase-positive cytoplasmic granules and an esterase-negative cell surface (Fig. 6). Some macrophages in the inflammatory peritoneal exudate labelled by the typical esterasepositive surface were found to have peroxidase-positive cytoplasmic vacuoles and/or granules (Fig. 6, arrow) thus confirming the observations reported above of inflammatory macrophages with peroxidase-positive sites.

\section{Kinetics of peritoneal neutrophil response to phlogistic agents}

The injection of casein, IFA and bacteria (Fig. 7A-D) resulted in strong inflammatory responses compared to PBS (Fig. 7E), carbon and sham injections. In the latter 3 situations, small perturbations occurred in neu- trophil numbers soon after treatment but values had returned to normal after several hours. Data from PBS injected fish (Fig. 7E) are representative of fish injected with India ink and sham-injected fish (not shown).

Neutrophilic responses to strong inflammation (casein, IFA and bacteria) are shown in Fig. 7A-D. In the case of live bacteria, neutrophil influx into the peritoneal cavity peaked at 24 to $48 \mathrm{~h}$ and resulted in a 500 -fold increase in number. Macrophage responses (Fig. $7 \mathrm{~A}-\mathrm{D}$ ) peaked at 2 to $4 \mathrm{~d}$ and the increase was comparatively more modest $(7.5 \times)$. In the case of IFA and bacteria, at $48 \mathrm{~h}$ the neutrophil numbers were greater than the macrophage number; casein neutrophil numbers were below but close to those of macrophages. The extensive influx of neutrophils into the peritoneal cavities injected with bacteria had almost completely subsided 8 d after the i.p. inoculation (Fig. 7 C, D). In the 3 situations of extensive inflammation the number of peritoned leucocytes had returned to normal after $15 \mathrm{~d}$, except in the case of IFA, when after $30 \mathrm{~d}$ the values were still slightly above normal (Fig. 7A-D).

Rainbow trout inoculated with $5 \times 10^{7}$ live Yersinia ruckeri recovered from the infection, as judged from the disappearance of the bacteria from the peritoneal exudates $4 \mathrm{~d}$ post-inoculation and from the absence of clinical signs of infection.

\section{Phagocytosis of bacteria by neutrophils and macrophages}

The distribution of phagocytosed bacteria in the 2 phagocytes of the peritoneal cavity of rainbow trout

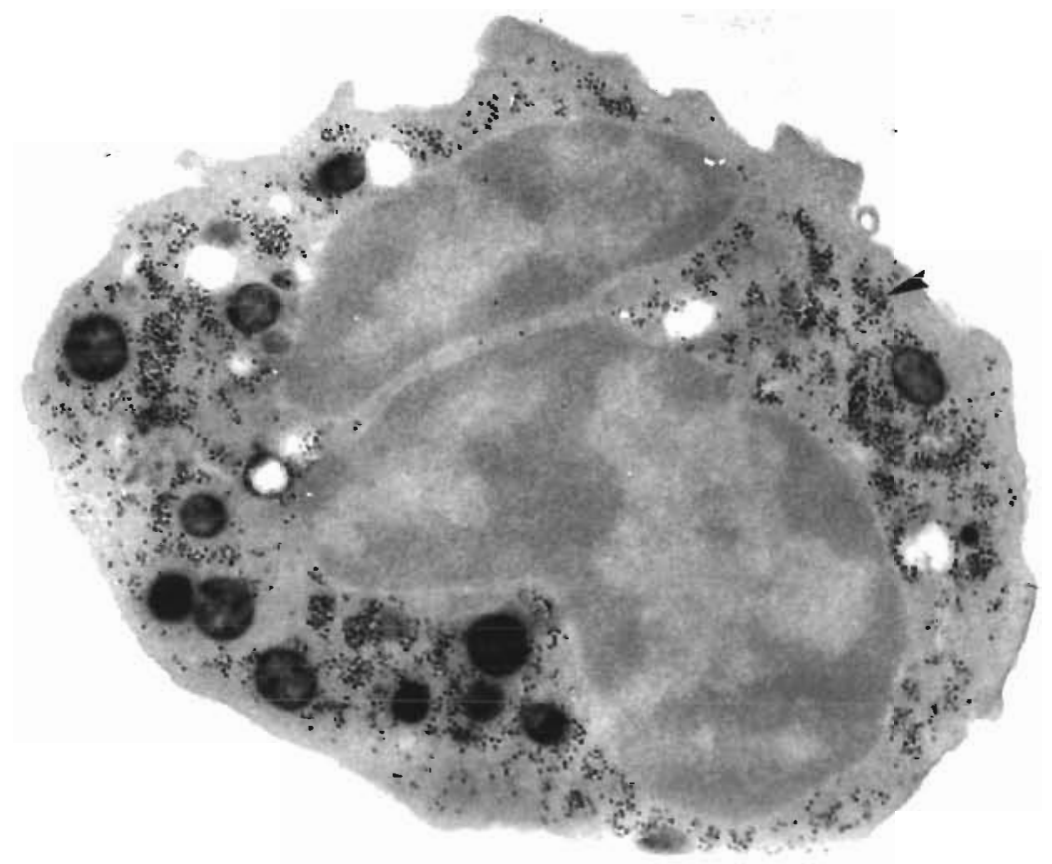

Fig. 3. Neutrophil in the peritoneal exudate of a trout $44 \mathrm{~h}$ after the injection of Incomplete Freund's Adjuvant (IFA) Sample processed for peroxidase and section stained for glycogen using Thiéry's method. Notice the peroxidase-positive cytoplasmic granules and the Periodic Acid-Schiff (PAS)-positive glycogen inclusions (arrowhead). $\times 15120$ 
Fig. 4. Electron micrograph of a macrophage in the peritoneal exudate of a rainbow trout $20 \mathrm{~h}$ after i.p. inoculation with live Yersinia ruckeri. Sample processed for peroxidase and postfixed with osmium tetroxide supplemented with potassium ferrocyanide. Notice the presence of peroxidase-positive cytoplasmic granules and vacuoles. Only a few scattered glycogen granules are visible in the cytoplasm (arrowhead). Section contrasted with lead citrate. $\times 13600$

Fig. 5. Macrophage from an unstimulated peritoneal cavity of a rainbow trout. Sample processed for alpha-naphthyl butyrate (ANB) esterase followed by peroxidase. Note the strongly esterase-positive cell surface and absence of peroxidase staining of the cytoplasmic granules. Section contrasted with lead citrate. $\times 9000$
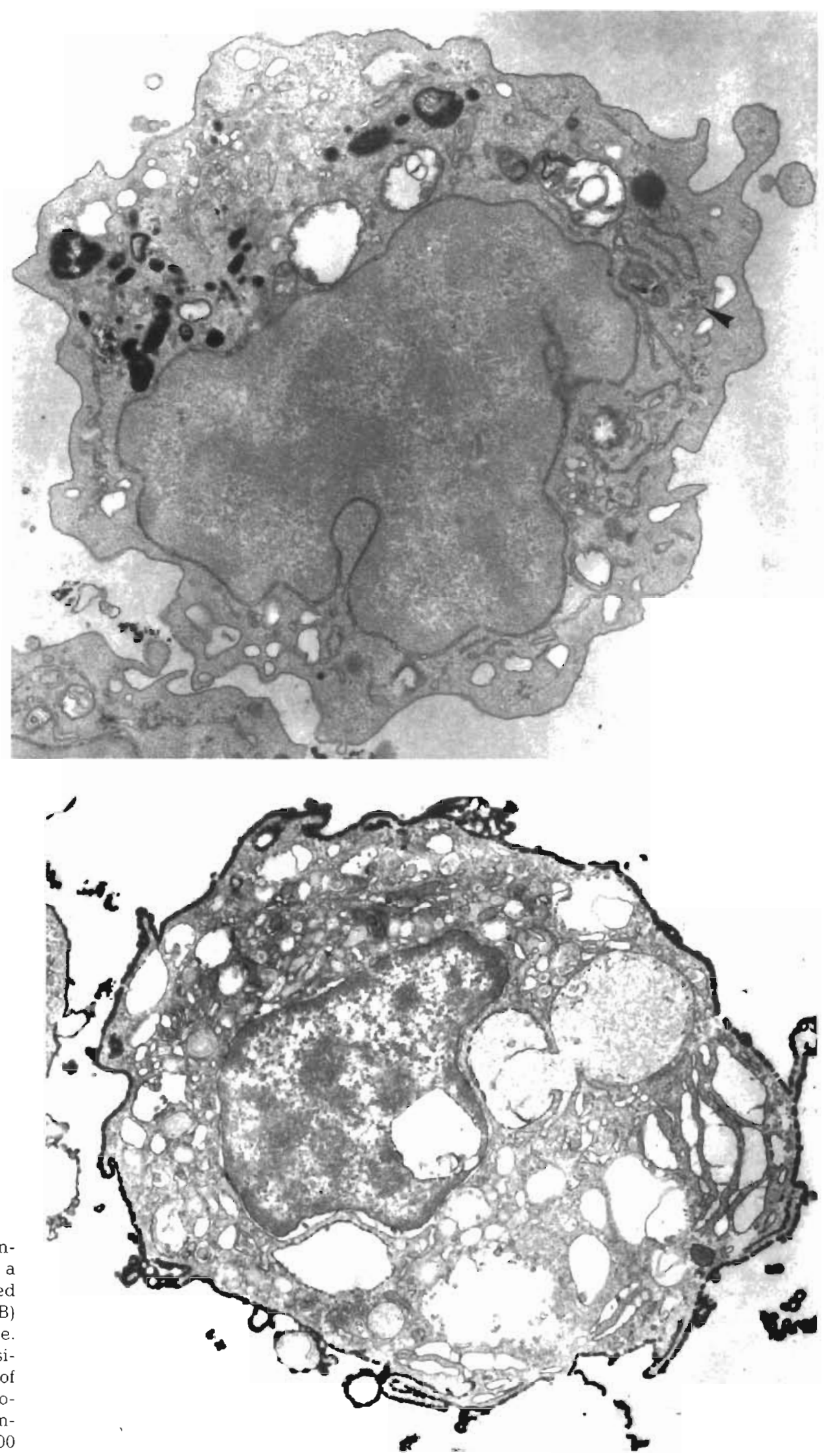


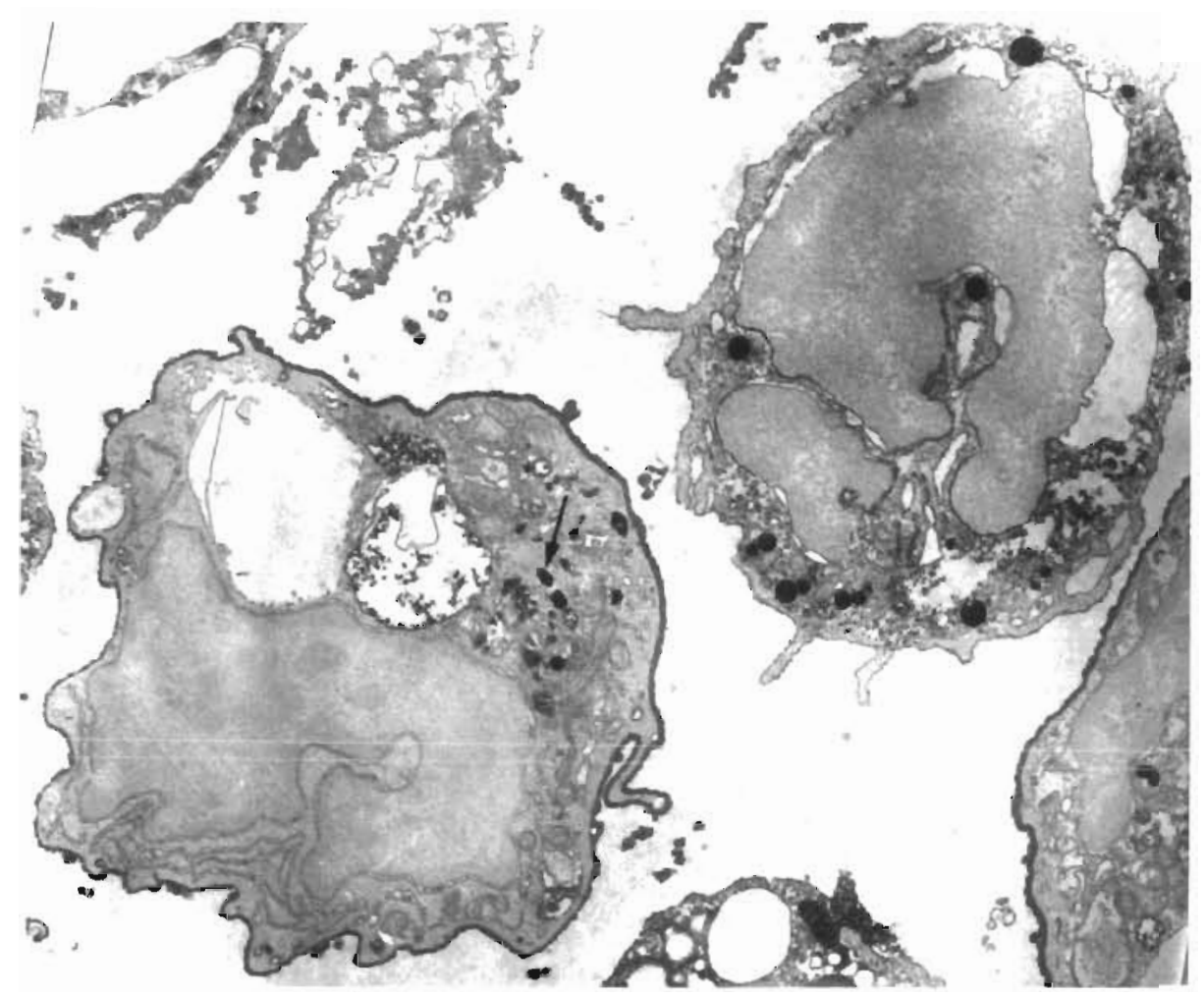

Fig. 6. Same sample as in Fig. 4 but processed for ANB esterase followed by peroxidase staining. Notice the neutrophil (right-hand side) with peroxidase-positive granules and no esterase staining of the cell surface. A macrophage, labelled by a strong esterase staining on its surface, contains several peroxidasepositive cytoplasmic granules (arrow) similar to those present in the neutrophil, and a large vacuole with peroxidase-positive material. Section stained with lead citrate. $\times 7600$
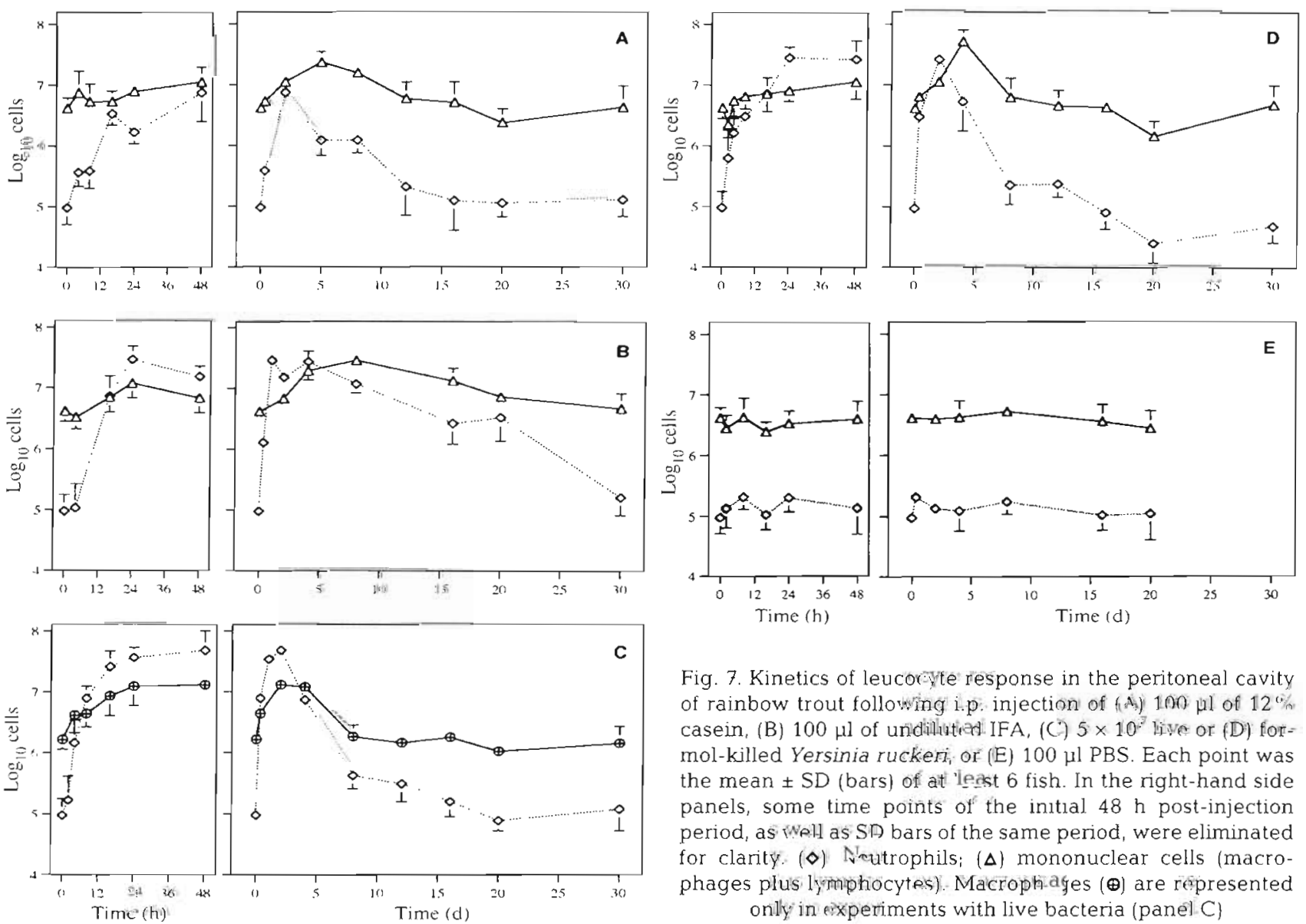

Fig. 7. Kinetics of leucocyte response in the peritoneal cavity of rainbow trout following i.p. injection of (A.) $100 \mu \mathrm{l}$ of $12 \%$ casein, (B) $100 \mu \mathrm{l}$ of undiluted IFA, (C) $5 \times 10^{7}$ live or (D) formol-killed Yersinia ruckeri, or (E) $100 \mu 1$ PBS. Each point was the mean $\pm S D$ (bars) of at least 6 fish. In the right-hand side panels, some time points of the initial $48 \mathrm{~h}$ post-injection period, as well as SD bars of the same period, were eliminated for clarity. $(\diamond)$ Neutrophils; $(\Delta)$ mononuclear cells (macrophages plus lymphocytes). Macrophages ( $\oplus$ ) are represented only in experiments with live bacteria (panel C) 
was analysed in cytospin preparations stained using Antonow's technique. Table 1 shows that following the injection of Yersinia ruckeri into the resting peritoneal cavity significantly more macrophages than neutrophils had ingested bacteria. However, this distribution of bacteria in the 2 phagocytes was changed when bacteria were injected into peritoneal cavities rendered inflamed by the previous injection of casein. In this case, a higher number of neutrophils than macrophages with ingested microrganisms was found, with percentages of neutrophils with bacteria approaching those of macrophages with bacteria (Table 2).

\section{Cytochemistry of blood monocytes}

Blood monocytes from normal trout were found by light and electron microscopy to be peroxidasenegative, esterase-positive and poor in glycogen granules (not shown).

\section{DISCUSSION}

One interesting aspect regarding the participation of phagocytosis in defence mechanisms to combat infection in trout, as in other vertebrates, is the utilization of 2 leukocytes with phagocytic capacities, the neutrophil and the macrophage. To obtain reliable, quantitative data on the participation of each of these phagocytes in antimicrobial mechanisms, an unequivocal distinction between them is necessary. Since neutrophils and macrophages in inflammatory sites in fish can be impossible to distinguish using simple morphological criteria, the present study used cytochemical techniques, including ultrastructural double-labellings (peroxidase followed by periodic acid-Schiff reaction, PAS, and peroxidase following ANB esterase).

Table 1 Number of peritoneal macrophages and neutrophils with bacteria after i.p. inoculation of $5 \times 10^{7}$ live Yersinia ruckeri into the unstimulated peritoneal cavity of rainbow trout (same experiment as in Fig. $7 \mathrm{C}$ ). $\mathrm{N}=6$. Number of macrophages or neutrophils with bacteria per 100 total macrophages or neutrophils given in parentheses. p-values (Student's $t$-test) for the comparison between number of macrophages with bacteria and number of neutrophils with bacteria were $\mathrm{p}<0.005$ for the 3 time points studied

\begin{tabular}{|ccrrr|}
\hline \multirow{2}{*}{$\begin{array}{l}\text { Time after } \\
\text { bacterial } \\
\text { challenge }(\mathrm{h})\end{array}$} & $\times 10^{4} \pm \mathrm{SD}$ & \multicolumn{3}{c|}{ Neutrophils } \\
& & & & \\
\hline 4 & $79.312 \pm 48.43$ & $(19.2)$ & $8.683 \pm 6.20$ & $(6.0)$ \\
8 & $66.372 \pm 32.23$ & $(15.17)$ & $14.839 \pm 6.44$ & $(1.9)$ \\
24 & $88.596 \pm 52.80$ & $(7.04)$ & $41.840 \pm 16.48$ & $(1.15)$ \\
\hline
\end{tabular}

Table 2. Number of peritoneal macrophages and neutrophils with bacteria in the peritoneal cavity of rainbow trout injected i.p. with live $3 \times 10^{8}$ Yersinia ruckeri 48 h after i.p. injection of $100 \mu$ of $12 \%$ casein. $N=5$. Number of macrophages or neutrophils with bacteria per 100 total macrophages or neutrophils given in parentheses. $p$-values (Student's t-test) for the comparison between number of macrophages with bacteria and number of neutrophils with bacteria were $p=0.360(6 \mathrm{~h})$. $p=0.144(8 \mathrm{~h})$ and $p<0.05(24 \mathrm{~h}) . \mathrm{p}$-values for the comparison of number of neutrophils with bacteria in Table 1 with number of neutrophils with bacteria in Table 2 were $p<0.005$ for 8 and $24 \mathrm{~h}$

\begin{tabular}{|cccccc|}
\hline $\begin{array}{l}\text { Time after } \\
\text { bacterial } \\
\text { challenge (h) }\end{array}$ & $\times 10^{4} \pm \mathrm{SD}$ & $(\%)$ & $\times 10^{4} \pm \mathrm{SD}$ & $(\%)$ \\
\hline 6 & $105.96 \pm 25.05$ & $(18.0)$ & $126.66 \pm 40.35$ & $(15.4)$ \\
8 & $177.89 \pm 72.75$ & $(23.0)$ & $257.24 \pm 81.83$ & $(19.9)$ \\
24 & $418.71 \pm 60.10$ & $(22.7)$ & $570.34 \pm 102.58$ & $(8.2)$ \\
\hline
\end{tabular}

Our results show that peroxidase staining is an essential label for neutrophils. The classical method of Kaplow is quite efficient for the purpose of detecting peroxidase activity in leukocytes, but the intense, dark-blue staining of neutrophil granules makes it difficult or impossible to visualize intraneutrophilic bacteria. Antonow's method as described herein, which results in a green staining of peroxidase-positive sites, allows for a clear visualization of both peroxidase activity and bacteria. Other advantages of Antonow's method over Kaplow's are the possibility of using Wright counterstaining, which makes it easier to classify leukocytes, and this method's insensitivity to light and long-term stability, which allows for the stocking of preparations over long periods of time.

In contrast to that which is reported for mammalian neutrophilic myeloperoxidase (Horton et al. 1996), we found that trout neutrophilic peroxidase is cyanideresistant. In this respect, peroxidase of trout neutrophils behaves like mammalian eosinophil peroxidase (Horton et al. 1996).

The present results show that peritoneal inflammatory macrophages, in contrast to resting resident macrophages (Afonso et al. 1997) and blood monocytes (present results), can have peroxidase activity. This might complicate the differential labelling of neutrophils and macrophages in inflamed areas. Our study shows, however, that an unambiguous distinction between the 2 phagocytes, even when macrophages are peroxidase-positive, can be achieved. Firstly, as described above, the patterns of peroxidase positivity in light microscopic preparations are different for neutrophils and macrophages. Secondly, the ultrastructural double-labellings (peroxidase + PAS, ANB esterase + peroxidase) allow for a clear characterization of peroxidase-positive phagocytes: neutrophils are strongly 
peroxidase-positive, esterase-negative and rich in glycogen granules, while peroxidase-positive macrophages are, like the peroxidase-negative macrophages and blood monocytes, esterase-positive and poor in glycogen granules. The double-labellings, moreover, permit the characterization of small portions of phagocytes, when most of the cellular details are not present in the picture as in the case with tangential sections (cf. Fig. 2). Details about the occurrence of peroxidasepositive macrophages in inflammatory peritoneal exudates of rainbow trout are given elsewhere (Afonso et al. 1998).

Taking advantage of the capacity of Antonow's technique for the simultaneous visualization of peroxidase activity and bacteria, we found that both the neutrophil and the macrophage of rainbow trout, given the opportunity, phagocytose bacteria. The much higher percentage of macrophages with bacteria compared to neutrophils when Yersinia ruckeri was injected into resting peritoneal cavities can be explained by the high predominance of the mononuclear phagocytes in the population receiving the injected bacteria. The opportunity for phagocytosis by the neutrophils that are attracted to the cavity following the injection of the bacteria will largely depend on the number of bacteria still extracellular at the time of neutrophil arrival. Such an opportunity will, obviously, be higher when the total number of bacteria injected is above the phagocytic capacity of the resident peritoneal macrophages. It is interesting that, when the injection of bacteria is made into cavities with a high number of neutrophils, these phagocytes extensively ingested bacteria, showing that the actual phagocytic index for the 2 phagocytes in a given situation significantly reflects the opportunity they have to encounter the infectious agent.

The results from previous (Afonso et al. 1997) and present studies show that in rainbow trout, as in the mouse, the 2 professional phagocytes display different patterns of localization in the normal host and mobilization into inflamed areas. The scant neutrophil population of the resting, non-inflamed peritoneal cavity of rainbow trout (Afonso et al. 1997) is quickly increased in intense inflammatory situations by an extensive influx of neutrophils attracted from the reserve pools in hematopoietic organs and blood. The important permanent population of resident peritoneal macrophages (Afonso et al. 1997) increases, as well, although less extensively and more slowly than the neutrophil population. This increase in macrophage number is presumably due to an influx of monocytes from the reserve pools, as is well documented for the mouse (de Bakker et al. 1985, Appelberg et al. 1991, Pestana 1994). It is worth stressing that at some early points in time after the injection of bacteria and IFA the number of neu- trophils was greater than the number of macrophages. The observation that $8 \mathrm{~d}$ after the inoculation of Yersinia ruckeri, when the fish had already recovered from the infection, the number of peritoneal neutrophils was very close to normal shows that neutrophil numbers can return rather quickly to basal values. This is explained by the short lifespan of neutrophils and represents an advantage for the host in the sense that the potentially harmful presence of these cytotoxic leucocytes in the tissues is shortened. The finding that $30 \mathrm{~d}$ after the i.p. injection of IFA neutrophil numbers were still above normal may well be interpreted as resulting from the very slow elimination of the adjuvant's mineral oil maintaining the inflammatory situation. This shows that an analysis of the peritoneal neutrophilic response may be useful for the study of new adjuvant substances.

Since the mobilization of phagocytes into the peritoneal cavity is similar to that found for tissues (van Furth 1992), the present results indicate, therefore, that in fish, like in mammals (Lehrer et al. 1988, Hasslet et al. 1989, Silva et al. 1989, van Furth 1992, Densen et al. 1995, Kubicka et al. 1996), macrophages are the tissue resident phagocytes while the neutrophils are present in tissues in significant numbers only in situations of inflammation and only as long as the inflammation persists.

Acknowledgements. The authors are grateful to Prof. C. J. Secombes (University of Aberdeen, UK) for continuous help and support, to Prof. Alberto Villena (University of León, Spain) for helpful discussions, and to Prof. António C. Castro for supplying the fish used in the present work. The excellent technical assistance provided by Mrs Paula M. Macedo, Miss Irene Barros and Mr Adào Silva is gratefully acknowledged.

\section{LITERATURE CITED}

Adams DO, Hamilton TA (1984) The cell biology of macrophage activation. Annu Rev Immunol 2:283-31.8

Afonso A, Ellis AE, Silva MT (1997) Leucocyte population of the unstimulated peritoneal cavity of rainbow trout (Oncorhynchus mykiss). Fish Shellfish Immunol 7:335-348

Afonso A, Silva J, Lousada S, Ellis AE, Silva MT (1998) Uptake of neutrophils and neutrophilic components by macrophages in the inflamed peritoneal cavity of rainbow trout (Oncorhynchus mykiss). Fish Shellfish Immunol 8: 319-338

Appelberg R (1992) Macrophage inflammatory proteins MIP-1 and MIP- 2 are involved in T cell-mediated neutrophil recruitment. J Leucocyte Biol 52:303-306

Appelberg R, Pedrosa JM. Silva MT (1991) Host and bacterial factors control the Mycobacterium avium-induced chronic peritoneal granulocytosis in mice. Clin Exp Immunol 83: $231-236$

Bozdech MJ, Bainton DE (1981) Identification of alpha naphthyl butyrate esterase as a plasma membrane ectoenzyme of monocytes and as a discrete intracellular membrane bounded organelle in lymphocytes. J Exp Med 153:182-195 
Brown EJ (1995) Phagocytosis. BioEssays 17:109-117 de Bakker JM, De Wit AW, Onderwater JJM, Ginsel LA, Daems WT (1985) On the origin of peritoneal resident macrophages. I. DNA synthesis in mouse peritoneal resident macrophages. J Submicrosc Cytol 17:133-139

Densen P, Clark RA, Nauseef WM (1995) Granulocytic phagocytes. In: Mandell GL, Burnett JE, Dolin R (eds) Principles and practice of infectious diseases, 4 th edn. Churchill Livingstone, New York, p 78-102

Edwards D, Kirkpatrick CH (1986) The immunology of mycobacterial diseases. Am Rev Respir Dis 134:1062-1071

Ellis AE (1977) The leucocytes of fish: a review. J Fish Biol 11:453-491

Haslett C, Savill JS, Meagher L (1989) The neutrophil. Curr Opin Immunol 2:10-18

Hine PM (1992) The granulocytes of fish. Fish Shellfish Immunol 2:79-98

Horton MA, Larson KA, Lee JL, Lee NA (1996) Cloning of the murine eosinophil peroxidase gene ( $\mathrm{MEPO}$ ): characterization of a conserved subgroup of mammalian hematopoietic peroxidases. J Leukocyte Biol 60:285-294

Kaplow LS (1965) Simplified myeloperoxidase stain using benzidine dihydrochloride. Blood 26:215-219

Karnowsky MJ (1971) Use of ferrocyanide-reduced osmium tetroxide in electron microscopy. J Cell Biol 51:146 (abstract)

Kubicka U, Olszewski WL, Tarnowski W, Bielecki K, Ziólkowska A (1996) Normal human immune peritoneal cell: subpopulations and functional characteristics. Scand J Immunol 44:157-163

Lehrer RI, Ganz MD, Selsted ME, Babior BM, Curnutte JT (1988) Neutrophils and host defense. Ann Intern Med 109. $127-142$

Mackaness GB (1969) The influence of immunologically conmitted lymphoid cells on macrophage activity in vivo. J Exp Med 129:973-992

Pestana MNTS (1994) Resposta peritoneal precoce à inoculação de micobactérias. PhD thesis. University of Porto

Robbins D, Fahimi HD, Cotran RA (1971) Fine structural cytochemical localization of peroxidase activity in rat peritoneal cells, mononuclear cells, eosinophils and mast cells. $\mathrm{J}$ Histochem Cytochem 19:517-575

Editorial responsibility: Donald Evans,

Athens, Georgia, USA
Robinson JM, Karnowsky ML, Karnowsky MJ (1982) Glycogen accumulation in polymorphonuclear leucocytes and intracellular alterations that occur during inflammation. J Cell Biol 95:933-942

Rowley AF, Hunt TC, Page M, Mainwaring G (1988) Fish. In Rowley AF, Ratcliffe NA (eds) Vertebrate blood cells Cambridge University Press, Cambridge, p 19-128

Secombes CJ, Fletcher TC (1992) The role of phagocytes in the protective mechanisms of fish. Annu Rev Fish Dis $53-71$

Silva MT, Appelberg R, Silva MNT, Macedo PM (1987) [n vivo killing and degradtion of Mycobacterium aurum within mouse peritoneal macrophages. Infect Immun 55: 2006-2016

Silva MT, Macedo PM (1983) The interpretation of the ultrastructure of mycobacterial cells in transmission electron microscopy of ultrathin sections. Int J Lepr 51:225-234

Silva MT, Macedo PM (1987) Improved Thiéry staining for the ultrastructural detection of polysaccharides. J Submicrosc Cytol 19:677-681

Silva MT, Santos-Mota JM, Melo JVC, Carvalho-Guerra F (1971) Uranyl salts as fixatives for electron microscopy. Study of membrane ultrastructure and phospholipid loss in bacilli. Biochim Biophys Acta 233:513-520

Silva MT, Silva MN, Appelberg R (1989) Neutrophil-macrophage cooperation in the host defence against mycobacterial infections. Microbial Pathog 6:369-380

Sousa MI (1994) Cooperaçāo neutrófilo/macrófago na infecção pelo Toxoplasma gondii. PhD thesis, University of Porto

Thiéry JP (1967) Mise en évidence des polysaccharides sur coupes fines en microscopie électronique. J Microscopie $6.987-1018$

Thuvander A, Norrgren L, Fossum C (1987) Phagocytic cells in blood from rainbow trout, Salmo gardneri (Richardson), characterized by flow cytometry and electron microscopy. J Fish Biol 31:197-208

van Furth R (1992) Development and distribution of mononuclear phagocytes. In: Gallin JI, Goldstein IM, Snyderman $\mathrm{R}$ (eds) Inflammation: basic principles and clinical correlates, 2nd edn. Raven Press Ltd, New York, p 325-339

Submitted: January 20, 1998; Accepted: June 3, 1998

Proofs received from author(s): September 4, 1998 